\title{
Paediatric Biobanks: Opinions, Feelings and Attitudes of Parents towards the Specimen Donation of Their Sick Children to a Hypothetical Biobank
}

\author{
Elena Salvaterra ${ }^{\mathrm{a}}$ Federica Locatelli ${ }^{\mathrm{b}}$ Sandra Strazzer ${ }^{\mathrm{b}}$ Renato Borgatti ${ }^{\mathrm{c}}$ \\ Grazia D'angelo ${ }^{d}$ Leonardo Lenzi ${ }^{a, e}$ \\ ${ }^{\mathrm{a} B i o e t h i c s ~ U n i t, ~}{ }^{\mathrm{b}}$ Acquired Brain Injuries Unit, ${ }^{\mathrm{c} C h i l d}$ and Adolescent Neuropsychiatry Unit, and \\ ${ }^{d}$ Neuromuscular Diseases Unit, Scientific Institute IRCCS 'E. Medea', Associazione La Nostra Famiglia, Bosisio Parini, and \\ eDepartment of Theology, Catholic University of the Sacred Heart, Milano, Italy
}

\section{Key Words}

Parent opinions · Focus groups · Sick children · Paediatric biobanks · Neurological diseases

\begin{abstract}
Over the last years, the storing of biological materials from children for research purposes in biobanks has become the subject of an intense debate in the scientific and ethical communities on a global level. Paediatric biobanks are an important resource for the development of translational research. At the same time, paediatric biobanks are ethically 'sensitive' due to the unique issues they raise. In this study, we explore opinions, feelings and attitudes of parents towards the specimen donation of their sick children to a hypothetical biobank. According to a qualitative methodology based on focus groups, we analysed parents' views, perceptions and inclinations towards typical ethical, legal and social aspects of paediatric biobanks such as proxy consent, minor assent, privacy protection and return of results. Our study confirms the need for specific policies dedicated to
\end{abstract}

paediatric biobanks by highlighting how the nature of the disease affecting children may influence the parents' opinions and decisions towards the enrolment of their children in biobank-based research studies.

(C) 2015 S. Karger AG, Basel

\section{Introduction}

Over the last decade, paediatric biobanks have become a subject of intense debate within the international community. On one hand, scientists recognise the importance of paediatric biobanks to promote translational research in the field of paediatrics $[1,2]$. Despite unique barriers such as small program size, fewer subjects, difficulties in sample collection techniques and limited tissue sample volumes, paediatric biobanks are recognised as being invaluable for providing scarce human material to meet the needs of children's health researchers [1]. On the other hand, however, paediatric biobanks are considered special in relation to the issues they raise ethically, legally and socially.

Dr. Elena Salvaterra

Scientific Institute IRCCS 'E. Medea' - Associazione La Nostra Famiglia Via D. L. Monza 20 
Many studies have analysed the ethical and legal aspects related to the collection, storage and use of newborn specimens for clinical applications [3-5]. Others consider the ethical and regulatory issues related to the recruitment, banking and use of child specimens for research purposes [6-8]. While speculative studies have focused on ethical issues of paediatric biobanks such as proxy consent, minor assent, privacy protection and return of results [9-11], empirical research has concentrated on interviews of health professionals $[12,13]$, parents [14-16] and the general public [17] regarding the involvement of children in biobank-based projects. Many of these studies have explored the parental opinions and attitudes towards the enrolment of healthy children in a hypothetical or existing biobank [18-21]. To date, few studies have analysed the views, perceptions or attitudes of parents about the participation of sick children in biobanks [14, 22, 23]. However, previous research $[24,25]$ concerning the involvement of paediatric patients in diagnostic tests or clinical trials have reported that numerous factors, including the nature of the disease, its severity and prognosis, may impact parental perception and understanding of the illness, and consequently influence their approach to the proposed medical treatments.

In light of the preceding research, this study seeks to explore the knowledge, feelings and attitudes of parents towards specimen donation of their sick children to a hypothetical biobank. Through focus groups involving parents of children affected with neurological disorders of acquired or genetic nature, the study aims to expand the current knowledge on this topic by determining whether the nature of the illness, its seriousness and the broader health conditions of the patient may influence parental decision-making about the participation of their children in biobanks.

\section{Methods}

A qualitative study was conducted using focus groups comprised of parents whose children suffered from acquired or inherited genetic neurological diseases.

\section{Sample and Participant Recruitment}

Parents whose children were seen during follow-up visits at the hospital (Scientific Institute IRCCS 'E. Medea') coordinating the research project or whose children were members of patient or family organisations collaborating with this hospital were invited to take part in the focus group study. Since the Scientific Institute IRCCS 'E. Medea' is a nationally recognised hospital dedicated to the treatment of neurological disorders of the developmental age, participants were selected on purpose to represent either acquired or inherited genetic illness in order to explore potential differences in parental knowledge, feelings and attitudes towards the participation of their children in a hypothetical biobank based on the nature and severity of the disease. Whereas encephalitis and traumatic brain injuries were selected among acquired neurological disorders, Duchenne dystrophy and Williams syndrome were chosen within the cluster of inherited genetic diseases. This selection was intended to form well-defined illness groups according to their nature (acquired vs. genetic).

Invitational letters to take part in the focus group study were distributed to eligible parents by physicians during hospital follow-up visits or meetings with the concerned patient or family organisations. Parents willing to participate in the research study received a description of the project, indications related to the focus group organisation and informed consent forms. All materials used for the study, including the documents previously mentioned as well as the interview guide followed for the focus group development, were approved by the Ethics Committee of the Scientific Institute IRCCS 'E. Medea'.

Overall, 30 parents took part in the focus group study (table 1). Based on data collected from the introductory discussion, the parents who participated in the study had children ranging in age from pre-school to adolescence (table 2). Children's health conditions varied according to the nature and the stage of the disease at the time of the study (table 2). While many children affected with encephalitis and traumatic brain injuries presented with serious cognitive deficits, children with Duchenne dystrophy had good cognitive conditions but severe and progressive motor deficits. The majority of children affected by Williams syndrome had good cognitive, psychological and physical abilities.

Focus Group Development

Four homogeneous focus groups involving parents whose children were affected by neurological diseases of acquired $(n=2)$ or inherited genetic nature $(\mathrm{n}=2)$ were performed from April to July 2012 .

While three focus groups took place in a dedicated room of the hospital, one was located at the official site of the regional 'Williams Syndrome Family Organisation' for logistical reasons.

Focus groups were designed to explore parental opinions, feelings and attitudes towards the inclusion of their sick children in a hypothetical biobank. They were conducted on the basis of a semistructured interview guide organised around five topics: (1) knowledge of biobanks, (2) child participation (through specimen donation) in biobanks, (3) privacy protection, (4) parental consent and minor assent, and (5) return of results.

The interview guide was pilot-tested in a dedicated focus group to improve its cognitive validity, coherence and clarity. Focus groups were conducted by an experienced moderator and lasted 60-90 min. After each focus group, section information and explanations were provided by the moderator in order to promote the parents' understanding of the discussed topics. An assistant moderator participated in the focus groups to take notes about the discussions. Each focus group was audio-recorded and transcribed, and identifiers were removed from the transcripts.

\section{Data Analysis}

According to a qualitative approach, an inductive content analysis methodology [26] was chosen to analyse data collected through the focus groups. Content analysis is a research methodology which may be used both in qualitative and quantitative research. The inductive content analysis technique is usually recommended when previous knowledge about a phenomenon is lacking or fragmented [26]. Since parental opinions, feelings and attitudes to- 
Table 1. Parents' participation in the focus groups

\begin{tabular}{lllll}
\hline Focus group & Encephalitis & Traumatic brain injuries & Duchenne dystrophy & Williams syndrome \\
\hline $\begin{array}{l}\text { Parents } \\
\text { participating in the } \\
\text { focus groups, } \mathrm{n}\end{array}$ & $\begin{array}{l}6(1 \text { couple and } 4 \\
\text { individual parents })\end{array}$ & $\begin{array}{l}6 \text { (1 couple and } 4 \\
\text { individual parents })\end{array}$ & $\begin{array}{l}7 \text { (3 couples and } 1 \\
\text { individual parent) }\end{array}$ & $\begin{array}{l}11(3 \text { couples and } 5 \\
\text { individual parents })\end{array}$ \\
\hline
\end{tabular}

Table 2. Information related to sick children whose parents participated in focus groups

\begin{tabular}{lllll}
\hline Focus group & Encephalitis & Traumatic brain injuries & Duchenne dystrophy & Williams syndrome \\
\hline Age & pre-school and school age & pre-school and school age & school age & school age \\
\hline $\mathrm{n}$ & 5 & 5 & 4 & 8 \\
\hline $\begin{array}{l}\text { Health conditions } \\
\begin{array}{l}\text { at the time of the } \\
\text { focus group }\end{array}\end{array}$ & $\begin{array}{l}\text { serious cognitive deficits } \\
(\mathrm{n}=4), \text { progressive motor } \\
\text { deficits }(\mathrm{n}=1)\end{array}$ & $\begin{array}{l}\text { severe cognitive deficits } \\
(\mathrm{n}=5)\end{array}$ & $\begin{array}{l}\text { good cognitive } \\
\text { conditions }(\mathrm{n}=4),\end{array}$ & $\begin{array}{l}\text { good cognitive, psychological } \\
\text { and physical abilities }(\mathrm{n}=4), \\
\text { relevant cognitive deficits } \\
(\mathrm{n}=2), \text { severe physical } \\
\text { deficits }(\mathrm{n}=2)\end{array}$ \\
\hline
\end{tabular}

wards the inclusion of sick children in biobanks is still largely unexplored in speculative as well as empirical research, inductive content analysis methodology was chosen as most appropriately fitting to the scope of the study. According to this method, focus groups' transcribed data were cross-checked with audio files and notes for accuracy. All transcripts were reviewed with notes and headings written in the text. Based on written comments, lists of concepts were generated and then organised in broader higherorder categories [27-30] describing the explored topic.

\section{Results}

In line with the methodology used, focus group data related to parental opinions, feelings and attitudes were organised into the following categories: (1) knowledge and perceptions of biobanks, (2) attitudes and motivations to donate child specimens to a hypothetical biobank, (3) concerns and risks of child participation in biobanks, (4) children's decision-making processes, and (5) research result handling.

\section{Knowledge and Perceptions of Biobanks}

Many parents whose children were affected by encephalitis $(n=3)$ and traumatic brain injuries $(n=4)$ did not have a clear understanding of biobanks. Two parents linked biobanks to 'blood donation' or 'freezers'. Nevertheless, many shared the perception of biobanks as a 'source of hope' and often associated these with promising research development. On the contrary, most parents $(n=15)$ whose chil- dren were affected by inherited genetic diseases were familiar with the concept of biobanks and had a good understanding of them. Among these participants, the most recurrent definition of biobank was that of 'a facility collecting biological material, like cord blood or tissues'.

\section{Attitudes and Motivations to Donate Child Specimens to a Hypothetical Biobank}

Regardless of the nature and severity of the disease, most parents agreed to donate the biological material of their children to a biobank $(n=29)$. Some parents perceived child specimen donation to a biobank as 'an important thing, a good thing to do' or 'a fair good'. Only one mother did not support the enrolment of her child into a biobank. She said that 'donating samples from my son to a biobank is completely worthless because his disorder was caused by a traumatic event', indicating that research associated with traumatic brain injuries would not benefit from biobank-based studies.

Apart from this position, research development was indicated as the main reason to donate the child specimens to a biobank. However, which research should be promoted and which aims should be achieved through new or ongoing studies were widely controversial.

Among parents whose children were affected by traumatic brain injuries and Duchenne dystrophy, 'helping others' was the main motivation for supporting the child specimen donation to a biobank $(n=9)$. 'For me the concept of donation is part of the life itself, commented a par- 
ent of the traumatic brain injury focus group. Another parent from the Duchenne dystrophy group said: 'I think that my daughter would be happy to donate. She would be proud of herself. Accordingly, the parent support for the child specimen donation to a biobank was mostly intended to promote the research development regardless of the disease affecting their children $(\mathrm{n}=10)$. Different feelings were expressed from parents of other focus groups. Several participants of the encephalitis group hoped that the research using their child's specimens could lead to benefits for themselves $(\mathrm{n}=4)$. Likewise, several parents whose children were affected by Williams syndrome expected individual benefits for their children $(n=5)$. One parent said: 'I have a sense of trust that a biobank, in general, could help our children to have better quality of life'.

\section{Child Participation in Biobanks: Concerns and Risks}

Apart from the concern that the child specimens could be used for illegal purposes (e.g. the development of 'bacteriological arms'), most parents shared the fear that enrolment of children in a biobank could hurt them physically. One mother said: 'I would not authorize the child sample donation to a biobank if this would entail the use of invasive techniques'. Privacy failure was not perceived as a risk by many parents $(n=26)$. Some participants of the Williams syndrome focus group reported concerns about potential breaches of the privacy protection, while other parents thought that the privacy of their children was not a problem. 'When you make a donation of biological materials to a biobank, you perform an action of trust', one parent commented. Many parents thought that the privacy of their children should be protected with adequate measures permitting donor identification when necessary.

\section{Children's Decision-Making Process}

Many parents agreed that their children should be informed about the donation of their specimen to a biobank $(\mathrm{n}=26)$. A parent from the Duchenne dystrophy focus group explained: 'They want it; our children want to be informed'. Many parents also supported the active participation of their children in the decision-making process related to their enrolment in a biobank $(\mathrm{n}=24)$. The capacity to understand the information and express autonomous opinions was seen by most parents as a necessary condition to authorize their children's involvement in the decision-making process $(n=27)$. However, which capacities should be considered was mostly controversial. One parent of the Duchenne dystrophy focus group said, 'It is not enough to understand the sense of the donation of samples, but it is necessary to consider the emotional re-

Parents' Opinions and Attitudes on

Research Biobanks sponses of our children to this option, their fears and feelings'. Likewise, many participants of the Williams syndrome group emphasized the importance to consider both psychological and cognitive abilities. The time for recognising these capacities was also a point of contention, even though many parents thought that 10 years was a good age reference. Moreover, the age for recognition of legal capacity was seen by many participants as appropriate to give valid informed consent or to re-contact the children for obtaining a new or renewed informed consent.

\section{Research Result Handling}

All parents wanted to be informed about the research results. One parent of the traumatic brain injury focus group said: 'It is not important whether positive or negative, I would like to be informed about the research results'. Many participants of the Williams syndrome group expressed a sense of frustration deriving from the lack of results communication in previous research involving their children $(\mathrm{n}=8)$.

The person who should receive this information was mostly a point of disagreement. Some parents identified themselves as legitimate recipients of the results $(n=6)$. Others thought that the research results should be communicated to their children by their physician $(n=5)$. One parent proposed to ask for their children to indicate a preference. He said: 'It is important consider a person who our children trust'. However, the means of communicating the research results was not controversial. Most parents said that research results should be communicated to them and their children during a dedicated follow-up visit.

\section{Discussion}

According to previous research [31-33], this study confirmed a general willing attitude of parents to permit the enrolment of their children in biobank-based studies. Furthermore, it showed that this tendency is supported by parents of sick children, regardless of the nature of their diseases.

It also highlighted that 'helping others' and 'research advances' were the main motivations behind the parental decision to donate their children's specimens to a hypothetical biobank. Although these data confirmed previous studies, feelings and perceptions expressed by several focus group participants introduced new elements of discussion such as different ethical approaches of interviewed parents to biobanks. Whereas many parents wanted to donate their children's samples to a biobank for solidarity reasons, oth- 
ers supported the enrolment of their children in biobank studies mostly for personal benefits, including the advancement of research in the specific field of their child's disease.

The influence of the disease did not raise specific differences with regard to other topics explored in the focus group study, including privacy protection measures and the children's involvement in the decision-making process regarding the use of their specimens. Most parents were not concerned about their children's privacy protection and supported the children's participation in decisions related to their involvement in biobanks according to their cognitive, psychological and emotional abilities. Nevertheless, the focus groups were partly conditioned from the kind of disease affecting the children of interviewed parents.
By showing that certain factors such as the nature of the disease and its severity may influence some aspects of the parental decision-making about the enrolment of their children in a biobank, this study provides data supporting the development of policies dedicated to paediatric biobanks.

\section{Acknowledgements}

We would like to thank the parents participating in focus groups, their sick children and the patients' organisations for their important contributions to this study. We are also grateful to Dr. Lainie Friedman Ross (University of Chicago) for sharing materials helpful for developing the focus group interview guide.

\section{References}

$\checkmark 1$ Brisson AR, Matsui D, Rieder MJ, Fraser DD: Translational research in paediatrics: tissue sampling and biobanking. Pediatrics 2012;129: 153-162.

2 Barnes MG, Lynch JA, Corsmo JJ, et al: Biobanking in pediatric research; in Hutton JJ (ed): Pediatric Biomedical Informatics. Berlin, Springer, 2012.

-3 Sugarman J, Kaalud U, Kodish E, et al: Ethical issues in umbilical cord blood banking. JAMA 1997;278:938-943.

4 Salvaterra E, Lecchi L, Gobbi S, Rebulla P: The ethics of cord blood banking in light of ownership, informed consent and solidarity. Cell Preserv Technol 2006;4:91-96.

5 Burgio GR, Gluckman E, Locatelli F: Ethical reappraisal of 15 years of cord blood transplantation. Lancet 2003;361:250-252.

6 Hens K, Nys H, Cassiman JJ, Dierickx K: Risks, benefits, solidarity: a framework for the participation of children in genetic biobank research. J Pediatr 2011;158:842-848.

7 Avard D, Black L, Samuël J, et al: Best practices for research involving children and adolescents: genetic, pharmaceutical and longitudinal studies. Maternal Infant Child and Youth Research Network (MICYRN). Montreal, Centre of Genomic and Policy, 2012.

8 Hens K, Van El CE, Borry P, et al: Developing a policy for paediatric biobanks: principles for good practice. Eur J Hum Genet 2013;21:2-7.

-9 Gurwitz D, Fortier I, Lunshof JE, Knoppers BM: Research ethics. Children and population biobanks. Science 2009;325:818-919.

10 Hens K, Lévesque D, Dierickx K: Children and biobanks: a review of the ethical and legal discussion. Hum Genet 2011;130:403-413.

-11 Samuel J, Knoppers BM, Avard D: Paediatric biobanks: what makes them so unique? J Paediatr Child Health 2012;48:E1-E3.

-12 Salvaterra E, Giorda R, Bassi MT, et al: Pediatric biobanking: a pilot qualitative survey of prac- tices, rules and researcher opinions in ten European countries. Biopreserv Biobank 2012;10: 29-36.

13 Brothers KB: Biobanking in paediatrics: the human nonsubjects approach. Pers Med 2011; 8:79.

14 Klima J, Fitzgerald-Butt SM, Kelleher KJ, et al: Understanding of informed consent by parents of children enrolled in a genetic biobank. Genet Med 2014;16:141-148.

15 Brothers KB, Clayton EW: Parental perspectives on a pediatric human non-subjects biobank. AJOB Prim Res 2012;3:21-29.

16 Harris ED, Ziniel SI, Amatruda JG, et al: The beliefs, motivations and expectations of parents who have enrolled their children in a genetic biorepository. Genet Med 2012;3:330-337.

17 Kaufman D, Geller G, Leroy L, et al: Ethical implications of including children in a large biobank for genetic-epidemiologic research: a qualitative study of public opinion. Am J Med Genet C Semin Med Genet 2008;148C:31-39.

18 Williamson E, Goodenough T, Kent J, Ashcroft $\mathrm{R}$ : Children's participation in genetic epidemiology: consent and control; in Tutton R, Corrigan O (eds): Genetic Databases: Socio-Ethical Issues in the Collection and Use of DNA. London, Routledge, pp 139-160.

19 Stolt GU, Liss PE, Svensson T, Ludvigsson J: Attitudes to bioethical issues: a case study of a screening project. Soc Sci Med 2002;54:13331344.

20 Neidich AB, Jospeh JW, Ober C, Friedman Ross L: Empirical data about women's attitudes towards a hypothetical pediatric biobank. Am J Hum Genet 2008;146A:297-304.

21 Jenkins MM, Reed-Gross E, Rasmussen SA, et al: Maternal attitudes toward DNA collection for gene-environment studies: a qualitative research study. Am J Med Genet 2009;2378-2386.

22 Dixon-Woods M, Wilson D, Jackson C, et al: Human tissue and 'the public': the case of child- hood cancer tumour banking. BioSocieties 2008;3:57-80.

23 Elliot JG, Ford DL, Beard JF, et al: Informed consent for the study of retained tissues from post-mortem examination following sudden infant death. J Med Ethics 2008;34:742-746.

24 Lipstein EA, Nabi E, Perrin JM, et al: Parents' decision-making in newborn screening: opinions, choices, and information need. Pediatrics 2010;126:696-704.

25 Shilling V, Young B: How do parents experience being asked to enter a child in a randomised controlled trial? BMC Med Ethics 2009; 10:1.

26 Elo S, Kyngas H: The qualitative content analysis process. J Adv Nurs 2008;62:107-115.

27 Moretti F, van Vliet L, Bensing J, et al: A standardized approach to qualitative content analysis of focus group discussions from different countries. Patient Educ Couns 2011;82:420428.

28 Burnard P: A method of analysing interview transcripts in qualitative research. Nurse Educ Today 1991;11:461-466.

29 Hsieh HF, Shannon SE: Three approaches to qualitative content analysis. Qual Health Res 2005; 15:1277-1288.

30 Cavanagh S: Content analysis: concepts, methods and applications. Nurse Res 1997;4:5-16.

-31 Halverson CM, Ross LF: Attitudes of AfricanAmerican parents about biobank participation and return of results for themselves and their children. J Med Ethics 2012;38:561-566.

32 Lemke AA, Wolf WA, Hebert-Beirne J, et al: Public and biobank participant attitudes toward genetic research participation and data sharing. Public Health Genomics 2010;13:368-377.

33 Tabor HK, Brazg T, Crouch J, et al: Parent perspectives on pediatric genetic research and implications for genotype-driven research recruitment. J Empir Res Hum Res Ethics 2011;6: 41-52. 